\title{
THE ANALYSIS OF RATIONAL COMPONENT PARAMETERS FOR STRESS RIBBON THROUGH STEEL ARCH FOOTBRIDGES
}

\author{
Vilius KARIETA* \\ Vilnius Gediminas Technical University, Sauletekio al. 11, LT-10233 Vilnius, Lithuania \\ Received 18 May 2018; accepted 17 October 2018
}

\begin{abstract}
The article discusses the main component parameters and their interdependencies for a composite stress ribbon trough arch structure. The paper presents a methodology for balancing the combined suspension through arch steel bridge structure, suggests analytical methods for putting together the bearing components of the bridge and considers rational component parameters.
\end{abstract}

Keywords: stress ribbon bridge, steel bridge, arch bridge, equilibrium structure, rational component parameters, symmetrical loads, geometrically nonlinear analysis.

\section{Introduction}

A stress ribbon suspension structure appears as one of the most efficient, cost-effective and graceful types of suspension bridge constructions. Due to its properties and geometric shape, these structures are most commonly used for building footbridges (Schlaich et al., 2005; Strasky, 2005). The main bearing components of the stress ribbon bridge include high-strength steel cables, sheets or beams (Juozapaitis, Vainiūnas, \& Kaklauskas, 2006; Strasky, 2005; Schlaich et al., 2005; Sandovič, Juozapaitis, \& Kliukas, 2011). Stress ribbon suspension bridges are very effective when a strong natural foundation is used for rear supports (Strasky, 2005; Kulbach, 2007). Since the efficiency of stress ribbon suspension bridges increases along with a rise in the number of spans, multi-span structures are frequently employed (Troyano, 2003; Strasky, 2005; Sandovič, Juozapaitis, \& Gribniak, 2017). Nowadays, in order to avoid unwanted vibrations, a variety of mechanical and hydraulical dampers and shock absorbers are applied for flexible and lightweight stress ribbon bridge structures (Bleicher, Schauer, Valtin, Raisch, \& Schlaich, 2011). To increase the efficiency of suspension structures, composite materials started to be used for bearing components (Liu, Zwingmann, \& Schlaich, 2016). The main disadvantage of stress ribbon structures is large horizontal bearing reactions transmitted to the foundations, which often determines the cost of these structures (Schlaich et al., 2005; Kulbach, 2007; Karieta, 2010). At the end of the $20^{\text {th }}$ century, to create the new forms and to extend the limits of applying stress ribbon bridges, these structures were started to be combined with other bearing components seeking to use them in the structures of combined bridges (Karieta, 2017). The stress ribbon through the steel arch structure is one of such combined structures. This construction is specific because the arrangement of bearing components with opposing internal forces allows creating an equilibrium structure transmitting only vertical bearing reactions to the foundations (Strasky, 2005, 2008; Karieta, 2010, 2017). However, not much information about the behaviour and rational parameters of the composite stress ribbon through steel arch structure is provided.

The paper describes the main components geometric parameters and their interdependencies of the combined stress ribbon through steel arch structure, presents a methodology for balancing combined suspension through arch bridge structure, deals with analytical methods for putting together the bearing components of the composite bridge and considers rational component parameters.

\section{Component parameters for the equilibrium structure}

In his book, J. Strasky was one of the first to describe the idea of arranging the equilibrium stress ribbon supported on arch structure presented in Figure 1. (Strasky, 2005).

*Corresponding author. E-mail: vilius.karieta@vgtu.lt 
The diagram in Figure 1 shows that the arch can be used as an intermediate support. At the initial stage, the stress ribbon component can be considered as the structure of two spans supported on the saddle in the middle (Figure 1b). The analysis of the arch is carried out by loading it with self-weight, the weight of the saddle components and the pressure transmitted by the tendons of the stress ribbon component (Figure 1c). Structural parameters and initial strains in the arch and suspension component can be selected such that the horizontal forces of these structures be identical $\left(H_{a}=H_{v}\right)$. To uniform bearing reactions, struts can be used for combining the abutments of the stress ribbon component and the arch thus creating an equilibrium structure under vertical bearing reactions only (Figure 1d).

For simulating a composite structure, the application of digital methods is a complex and time-consuming task. This section provides a methodology for balancing the structure of the equilibrium suspension through arch bridge considering each particular case. The basic component parameters of the stress ribbon through the arch structure are provided in Figure 2: $L_{a}-\operatorname{arch}$ span; $f_{a}-$ the rising part of the arch; $L_{b}$ - the loaded part of the arch (length of the stress ribbon saddle); $L_{v}$ - the length of stress ribbon component; $f_{v}$ - a sag in the stress ribbon component; $h$ - the vertical distance between the supports; $S_{v}, S_{b}, S_{a}$ - the length of the geometric length of stress ribbon component, the saddle and the arch; $\beta_{g}$ - the tangent angle with a horizontal of the stress ribbon section
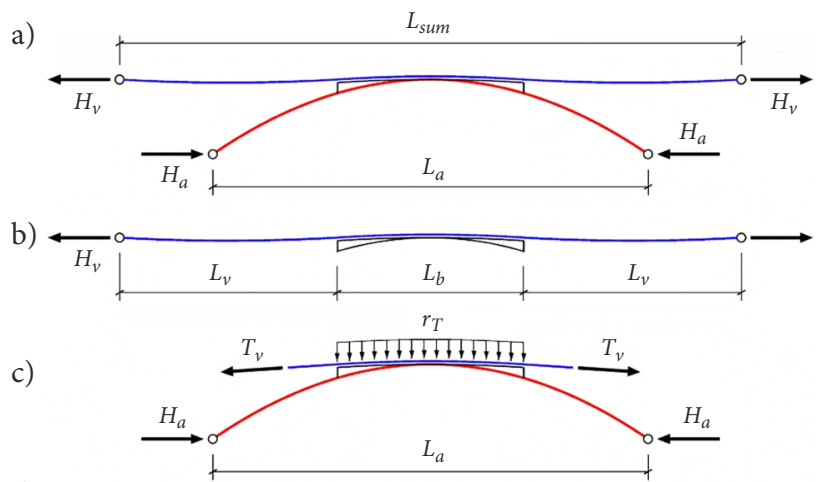

d)

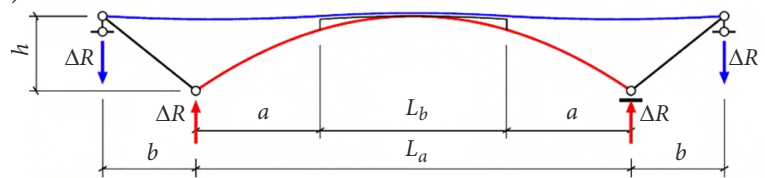

Figure 1. A component scheme for suspension through arch bridge

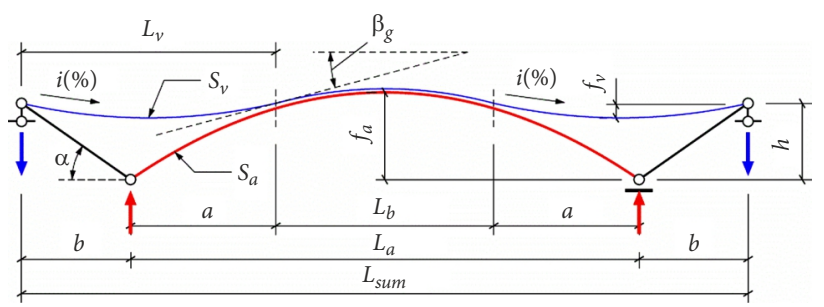

Figure 2. The main parameters of the bridge under permanent loads; $\alpha$ - the angle of the tilt of the bearing strut.

Geometric parameters presented in Figure 2 can be divided into groups to distinguish the main variables:

- Group 1. At the beginning of the arrangement, the initial parameters for the bridge $L_{a}, f_{a}, L_{\text {sum }}$ and $\mathrm{h}$ should be always known since they define the obstacle the bridge must overcome.

- Group 2. The initial parameters for the suspension part $\beta_{g}, i(\%), f_{v}$ describe suspension component sags usually limited by the needs of people with disabilities. Based on these parameters, the sag of the suspension component and its intermediate support, i.e. arch saddle, are determined.

- Group 3. The main variable $L_{b}$. Since the previously discussed geometric parameters should be always known at the beginning of arrangement, changing the value of parameter $L_{b}$ may assist in simultaneously adjusting the span of the suspension bridge and arch loading. The approximation method may help with balancing the bearing reactions of the main suspension components.

The arrangement of the balanced geometry of the composite bridge takes place under permanent loads of bearing components, and therefore defining materials, the cross-sections of bearing components and calculation methods for estimating horizontal bearing reactions is a crucial point at the beginning of the conducted analysis.

\section{The arrangement of the stress ribbon bearing section}

In the general case, the bearing reactions of stress ribbon section should be calculated taking into account the installation of the suspension component, the material of the bearing component (cables, steel sheets), cross-sectional structure (using steel profiles or reinforced concrete), etc. Subject to the type of stress ribbon structure, calculation methods are selected. In order to discuss the rational component parameters for the composite bridge, the paper presents the methodology for calculating the bearing reactions of the flexible single span cable, cross-sectional area and displacements under symmetrical loads. For calculating suspension structures and for determining the cross-sectional area of the bearing component, it is necessary to estimate the nonlinear behaviour of the bearing component. Thus, knowing the displacement of the bearing component at each stage of construction and assessing technology for construction and installation works are important points to be considered.

Figure 3 presents schemes for calculating the displacement of the stress ribbon component where $L$ - span; $f_{0}$ - the initial sag defining the initial geometry; $\Delta f_{\text {gnk }}$ displacement under permanent characteristic loads; $\Delta f_{v k}-$ displacement under variable characteristic loads; $f_{g k}-$ sag under permanent characteristic loads; $f_{g v k}$ - sag under permanent and variable characteristic loads; $\beta$ - the tangent angle of sag with a horizontal under permanent loads. 

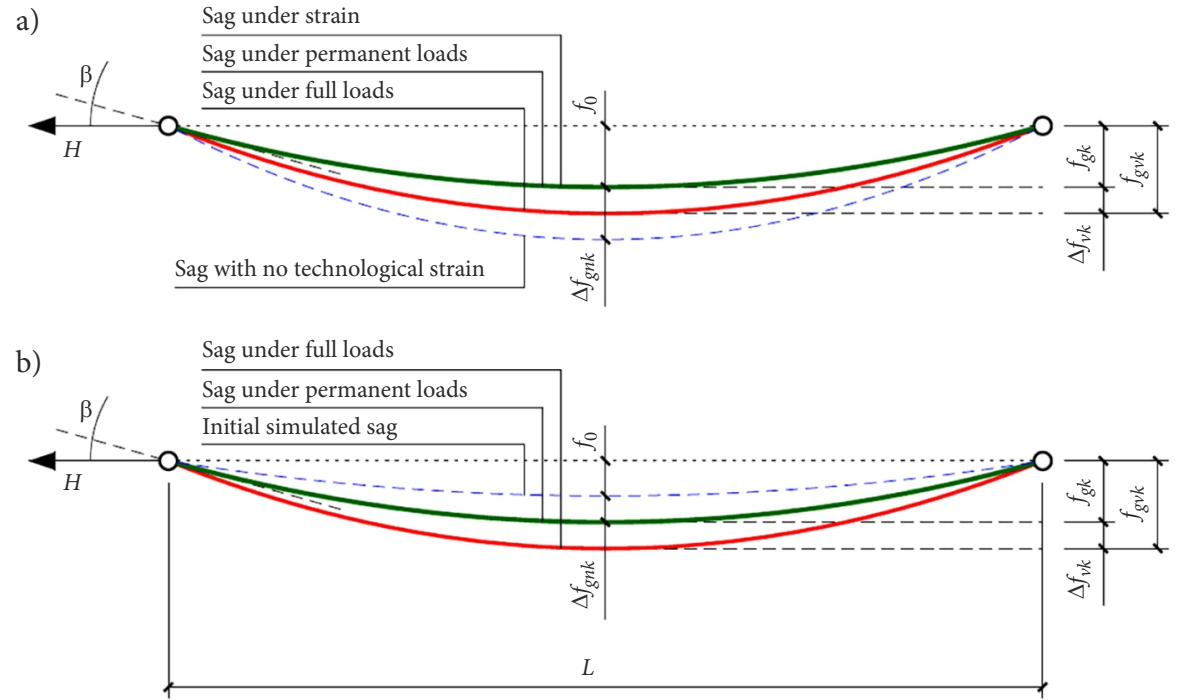

Figure 3. Displacements of symmetrically loaded cable: a) applying technological strain; b) without technological strain

The horizontal bearing reaction of both the suspension structure and the cross-sectional area are directly subject to sag. The bigger is the sag, the weaker is the horizontal reaction. However, for designing footbridges, the sag of the current part is usually limited by a longitudinal gradient, which may reach $8 \%$ for stress ribbon suspension bridges (Schlaich et al., 2005). This gradient can be expressed in degrees, and then angle $\beta=4.574^{\circ}$. Based on this condition, the permissible sag can be expressed through its tangent angle with horizontal $f_{g k}=(\operatorname{tg} \beta \cdot L) / 4$. Thus, in this case, we can always know the value of the sag of the current part at permanent loads under variations in its span.

Depending on the selected technology for installing a suspension structure (applying or omitting the strain of the bearing component), the cross-sectional area of the bearing component can be calculated thus selecting the initial geometric length of the component so that in each case sag should not exceed the condition of the allowable gradient of the current part and should meet requirements for the safety and appropriateness of the limit state. The cross-sectional area of the bearing component is selected according to the displacement of the bearing component under variable loads. The lower are limits on the displacement of the bearing component under variable loads, the more rational cross-sectional area can be applied to the bearing component. As for the latest European design standards, footbridges are not limited, which extends application limits on modern graceful structures. However, for designing footbridges, pedestrian comfort and technical-performance criteria must be taken into consideration. The cross-sectional area and displacement of the bearing component at various stages of construction can be calculated according to the following expressions.

When structures or installation technology of the suspension component allows strain on the bearing component (Figure 3a), the initial sag of the suspension component can be selected according to its sag under permanent loads $\left(f_{0}=f_{g k}\right)$. In this case, at constant loads, the bearing component will deform and shift at the value of $\Delta f_{g n k}$. In order to move back the bearing component to its original form, it is necessary to restore the initial state of the crosssection internal force. Therefore, the suspension component can be strained by the force equal to the horizontal bearing reaction at the initial stage $\left(F_{t}=H_{g k}\right)$. Next, the structure is subjected by variable loads and shifts at the value of $\Delta f_{v k}$ that depends on the selected cross-sectional area.

The displacement under characteristic variable loads is equal to:

$$
\Delta f_{v k}=\frac{L}{k},
$$

where $k$ - the coefficient of displacement increment $(100,200,300, \ldots)$.

The horizontal bearing reaction under characteristic permanent loads equals to:

$$
H_{g k}=\frac{g_{k} \cdot L^{2}}{8 \cdot f_{g k}} \text {. }
$$

The horizontal bearing reaction under characteristic full loads equals to:

$$
H_{g v k}=\frac{\left(g_{k}+v_{k}\right) \cdot L^{2}}{8 \cdot f_{g v k}} \text {. }
$$

The cross-sectional area of the bearing component is equal to:

$$
A=\frac{\left(H_{g v k}-H_{g k}\right) \cdot S_{g}}{\left[\frac{8}{3 \cdot L} \cdot\left(f_{g v k}^{2}-f_{g k}^{2}\right)\right] \cdot E},
$$

where $E$ - Young's modulus of the steel of the bearing component.

For designing a suspension structure with no strain, it is necessary to select the starting sag so that, under permanent loads, the suspension structure should shift at the 
value of $\Delta f_{g n k}$ and form the shape satisfying the condition for the permissible gradient of the current section (Figure $3 \mathrm{~b}$ ). To meet the condition of the permissible gradient in this particular case, the displacement of the suspension structure must be relatively small. The cross-sectional area of the structures for such construction technology is selected according to expressions (1)-(4), though in this case coefficient $k$ should be sufficiently high $(>325)$. By applying higher values of coefficient $k$, a larger crosssectional area of the bearing component is preferred thus simultaneously reducing the elastic displacement of the suspension component and behavioural non-linearity as well as taking easier control over the displacement of the suspension component.

The geometrical length of the suspension component under permanent characteristic loads is equal to:

$$
S_{g k}=L+\frac{8 \cdot f_{g k}^{2}}{3 \cdot L} .
$$

The displacement of the suspension component under permanent characteristic loads equals to:

$$
\Delta S_{g k}=\frac{H_{g k} \cdot S_{g k}}{E \cdot A} .
$$

The initial geometrical length of the suspension component is equal to:

$$
S_{g k}-\Delta S_{g k}=S_{0}>L
$$

The initial sag of the suspension component under no strain equals to:

$$
f_{0}=\sqrt{\frac{3 \cdot\left(S_{0}-L\right) \cdot L}{8}} .
$$

It should be emphasized that the cross-sectional area of the bearing components of single-lane suspension structures is selected according to the condition for the appropriateness of the limit state. Nevertheless, due to the geometrically nonlinear behaviour of suspension structures, this cross-sectional area will always meet the limit state of safety. Calculations according to expressions (1)-(8) show that the results are accurate and basically coincide with the results of the numerical geometrically nonlinear analysis. With reference to the expressions given, it is possible to determine the exact horizontal bearing reactions of the suspension component taking control over the displacement of the suspension component and evaluating the actual weight of the suspension component of the bridge in each case.

\section{The arrangement of the arched section}

When the internal forces of the suspension section are known, it is possible to prepare a calculation scheme for the component of the arch and to estimate the horizontal bearing reaction under permanent loads (Figure 1c). The internal force and behaviour of the arch can be determined on the basis of the behaviour of the equivalent beam having the same geometric length and stiffness. In this case, the arch is the once-statically unresolved struc- ture, and therefore bending stiffness EI of the arch has an effect on its displacement and internal stress. The horizontal bearing reaction considering the bending stiffness of the arch can be defined as follows:

$$
H \cong \frac{M_{m}{ }^{(0)}}{f_{a}}-\frac{48 \cdot E I \cdot \Delta f_{a}}{5 \cdot L_{a}{ }^{2} \cdot f_{a}},
$$

where: $\Delta f_{a}$ - vertical displacement of the centre of the arch, $L_{a}$ - arch span, $E I-$ bending stiffness of the arch, $M_{m}^{(0)}$ - a bending moment in the arch examining an equivalent beam, $f_{a}$ - the rising part of the arch.

One of the main tasks of arch analysis is to determine parameters for the arch cross-section in order to precisely ascertain self-weight having a significant impact on the horizontal bearing reaction of the arch. To design the arch considering requirements for strength and stability, it is required to know its precise design length in the case of the various combinations of arch loading. The approximate design length of the arch of the combined bridge can be defined by taking into account arch displacement described by the diagram of the bending moments of the arch. The analysis of the arch shows that when the stress ribbon is placed on the arch, the bending moments of the arch are established. The values of the bending moments of the arch under permanent loads vary along with the component parameters of the combined bridge, but the positions of variations in the signs of the diagram of bending moments remain similar and correspond to Figure 4. Hence, with reference to Figure 4, the approximate design length of the arch $l_{e f f}$ is a higher value of geometric length $S 1$ and $S 2$.

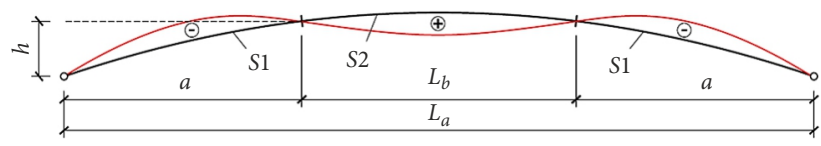

Figure 4. A diagram of the bending moments of the arch under permanent loads

\section{Rational component parameters for the stress ribbon through steel arch equilibrium bridge}

Calculations referring to formulas (1)-(9) and the scheme presented in Figure 2 show that each individual case provides a possibility of arranging the equilibrium structure of the combined bridge (when the bearing reactions of suspension and arched sections of the bridge are equal) (Figure 5).

In order to determine the parameters and their interdependencies of the combined steel equilibrium bridge, behavioural analysis due to permanent loads was performed using the following initial data: arch span $L_{a}=65.0 \mathrm{~m}$; loads of the stress ribbon section of the bridge: $g=7.5 \mathrm{kN} / \mathrm{m}, v=7.5 \mathrm{kN} / \mathrm{m}, \gamma=1.0$; stressed ribbon supports are at the same level (Figure 3). The small difference in horizontal bearing reactions is due to the vertical displacement of the arch, which should be taken into account in the detailed analysis of the bridge. 


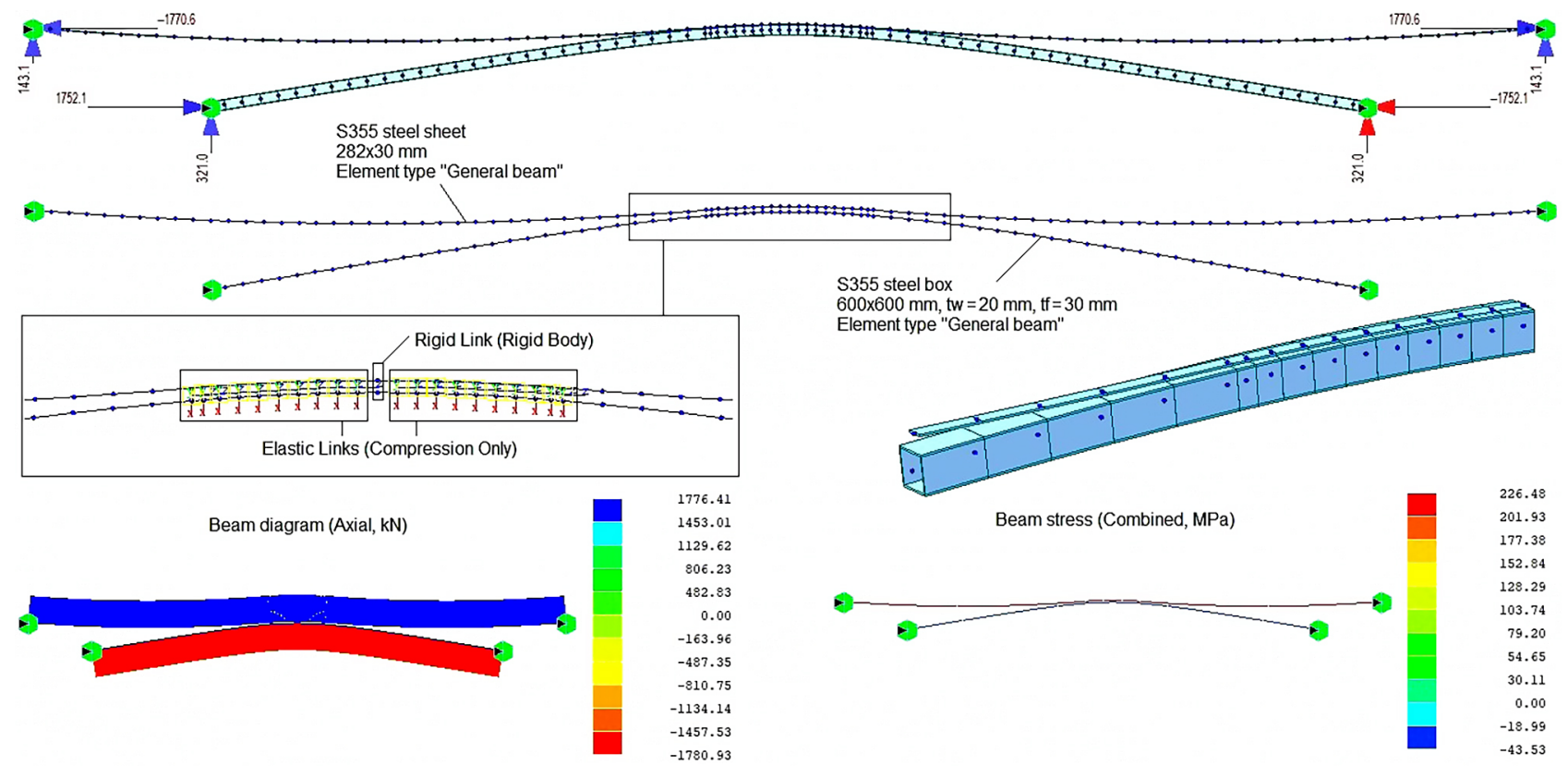

Figure 5. The bearing reactions of the nonlinear FEM analysis of the equilibrium composite structure: stress ribbon section $1770.6 \mathrm{kN}$; arched section $1752.1 \mathrm{kN}$

The analysis (using expressions (1)-(9)) of rational parameters for the combined bridge (when the horizontal reaction of the stress ribbon component is equal to the horizontal reaction of the arch) resulted in the diagram shown in Figure 6. The diagram illustrates variations in the length of the intermediate support (saddle) of the stress ribbon under changes in the rising part and weight of the arch.

Arch flexibility:

$\lambda=l_{\text {eff }} / i$.

The radius of the inertia of the arch cross-section:

$$
i=\sqrt{I / A} \text {, }
$$

where $l_{\text {eff }}$ - the calculated length of the arch; $I$ - the moment of inertia of the arch cross-section; $A$ - the crosssectional area of the arch.

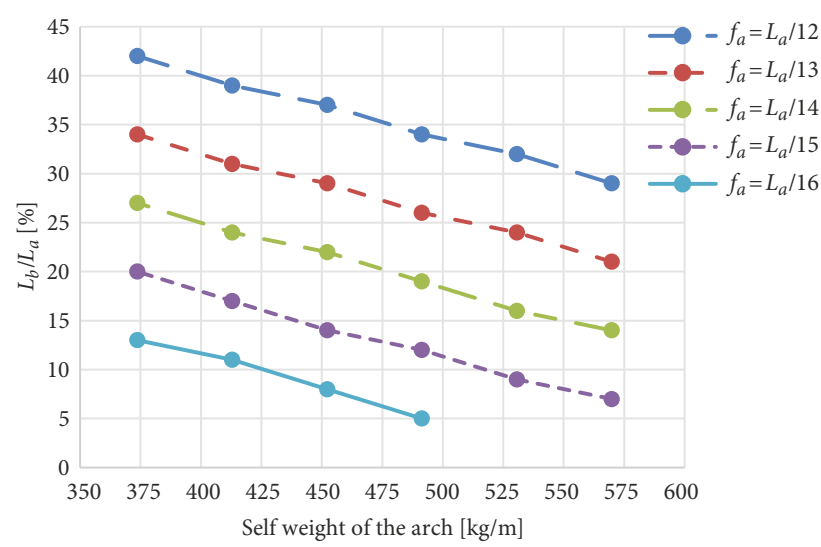

Figure 6. The dependence of the length of the loaded part of the arch on the self-weight and the rising part of the arch when the horizontal bearing reaction of the stress ribbon structure is equal to the thrust of the arch $\left(H_{v}=H_{a}\right) . L_{a}$ - arch span, $f_{a}$ - rising part of the arch, $L_{b}$ - the length of the intermediate support (saddle) of stress ribbon component
The arch is a curve which has a different radius than a curvature of the smooth part of the pedestrian path (with allowable gradients). The arched part of the saddle must properly support the stress ribbon section of the bridge. Increasing the cross-section of the arch leads to the additional amount of steel in the edges of the saddle. For this reason, the right geometric shape of the arc should be chosen in each case (Figure 7).

With reference to Figure 6, the range of the rising parts of the rational steel arches of the bridge can be determined. The presented diagram clearly shows the efficiency of extremely flat arches. While applying arches with low rising parts $\left(f_{a}=(1 / 16 \ldots 1 / 15) L_{a}\right)$, the area of the arched saddle is very small. When the rising part of the arch makes $(1 / 12) L_{a}$, the length of the saddle is equal to $42-29 \%$ of the arch span, which is the approximate limit from which the geometric shapes of the arched and suspension sections start to differ significantly and the length of the part of the suspension section of the bridge decreases sharply. Thus, it can be stated that the effective range of the rising parts of the steel arches for combined footbridge is $(1 / 16 \ldots 1 / 12)$ of the arch span.

\section{Conclusions}

The proper selection of component parameters for the bearing components of stress ribbon through arch bridges shows this structure can be balanced in such a way it should transfer only vertical bearing reactions to the foundations affected by loads (equilibrium structure is obtained).

The cross-sectional area of stress ribbon bearing component is selected according to the condition for the appropriateness of the limit state. The cross-sectional area 


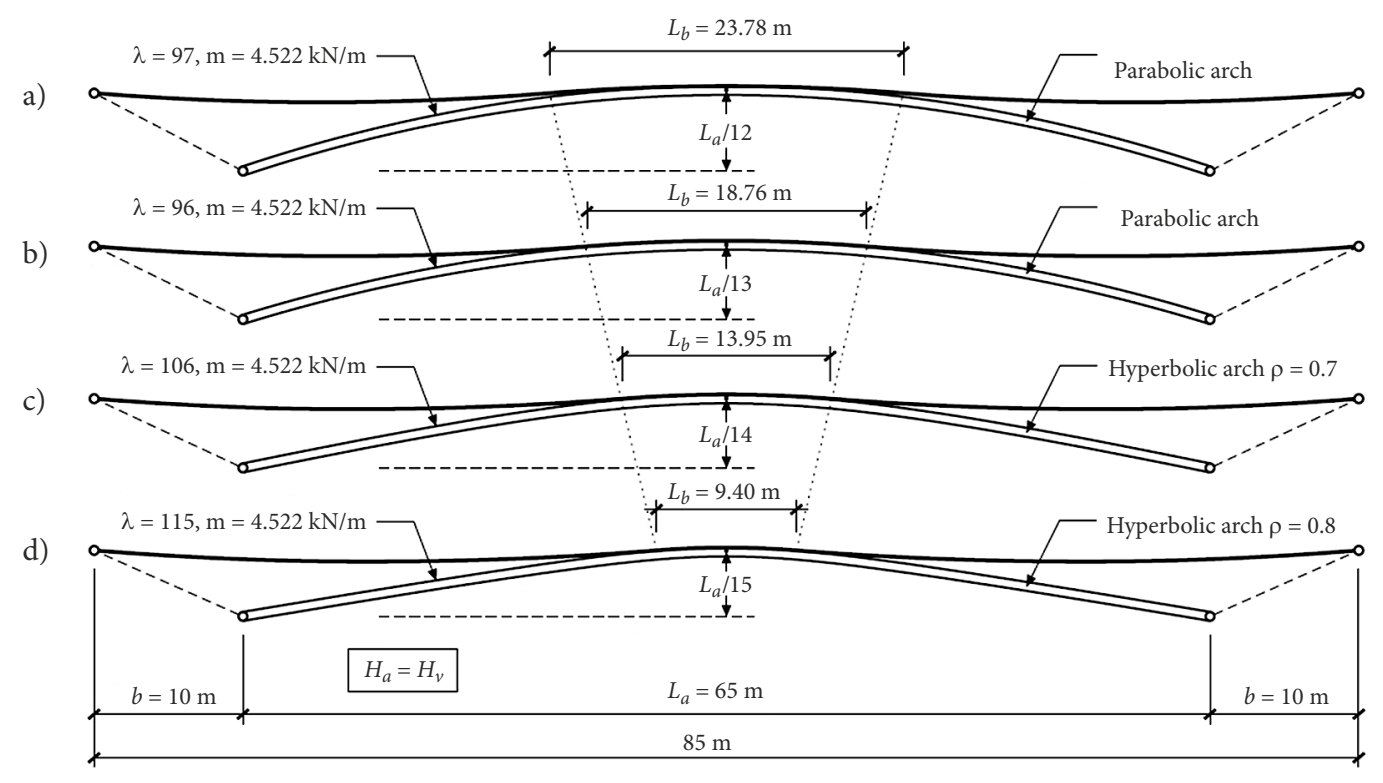

Figure 7. Parameters for the combined steel footbridge

has been found will always meet requirements for the limit state of safety.

According to expressions (1)-(8), the calculation results of the suspension bearing component is sufficiently accurate and basically coincide with the numerically obtained results of the geometrically nonlinear analysis. Based on the provided expressions, it is possible to determine the horizontal bearing reactions of the suspension bearing component taking control over the displacement of this component in each individual case.

In order to create an equilibrium structure of the composite bridge, the main rational component parameters for the bridge arch have been determined. The rational range of the rising parts of the arched section varies from 1/16 to $1 / 12$ of the arch span.

Stress ribbon structures of bridges are rational in terms of the cost of materials, and therefore it is important to consider the advantages of the suspension section in the structures of combined bridges. However, a rise in the length of the suspension section simultaneously increases axial forces in both bearing components. Hence, for creating the analyzed structure, it is important to exclusively focus on selecting the geometric shape of the arch and, certainly, on its stability analysis.

\section{References}

Bleicher, A., Schauer, T., Valtin, M., Raisch, M., \& Schlaich, M. (2011, August). Active vibration control of a light and flexible stress ribbon footbridge using pneumatic muscles. In Preprints of the $18^{\text {th }}$ IFAC World Congress, (pp. 911-916). Milano, Italy. https://doi.org/10.3182/20110828-6-IT-1002.02781

Juozapaitis, A., Vainiūnas, P., \& Kaklauskas, G. (2006). A new steel structural system of a suspension pedestrian bridge. Journal of Constructional Steel Research, 62(12), 1257-1263. https://doi.org/10.1016/j.jcsr.2006.04.023
Karieta, V. (2017). Vienajuosčiu kabamuju paremtu arka pėsčiuju tiltų pusiausvirosios sistemos komponavimas. Science - Future of Lithuania, 9(5), 495-499. https://doi.org/10.3846/mla.2017.1084

Karieta, V. (2010). Analysis of the single-lane suspension supported on arch pedestrian multispan bridge behaviour and research rational parameters (Master's thesis). Vilnius Gediminas Technical University, Lithuania.

Kulbach, V. (2007). Cable structures. Design and analysis. Tallin: Estonian Academy Publisher. 224 p.

Liu, Y., Zwingmann, B., \& Schlaich, M. (2016). Advantages of using CFRP cables in orthogonaly loaded cable structures. AIMS Materials Science, 3(3), 862-880.

https://doi.org/10.3934/matersci.2016.3.862

Sandovič, G., Juozapaitis, A., \& Gribniak, V. (2017). Experimental and analytical investigation of deformations and stress distribution in steel bands of a two-span stress-ribbon pedestrian bridge. Mathematical Problems in Engineering, 2017. Article ID 9324520. https://doi.org/10.1155/2017/9324520

Sandovič, G., Juozapaitis, A., \& Kliukas, R. (2011). Simplified engineering method of suspension two-span pedestrian steel bridges with flexible and rigid cables under action of asymmetrical loads. The Baltic Journal of Road and Bridge Engineering, 6(4), 267-273. https://doi.org/10.3846/bjrbe.2011.34

Schlaich, M., Brownlie, K., Conzett, J., Sobrino, J., Strasky, J., \& Takenouchi, K. (2005). Guidelines for the design of footbridges. Stuttgart: Sprint-Digital-Druck. 154 p.

Strasky, J. (2005). Stress ribbon and cable-supported pedestrian bridges. London: Thomas Telford Ltd. 232 p.

https://doi.org/10.1680/sracspb.32828

Strasky, J. (2008, July 10-14). Stress - ribbon pedestrian bridges supported or suspended on arches. In Chinese-Croatian Joint Colloquium "Long arch bridges", (pp. 135-148). Brijuni Islands.

Troyano, L. F. (2003). Bridge engineering: a global perspective. London: Tomas Telford Ltd. 775 p. https://doi.org/10.1680/beagp.32156 